\title{
Long-term Survival After Surgical Treatment of Spinal Metastasis - The Predictive Role of Sex
}

\author{
DENNIS KARIMI ${ }^{1}$, SØREN S. MORGEN ${ }^{1}$, SIDSEL FRUERGAARD $^{1}$, MARTIN GEHRCHEN $^{1}$ and BENNY DAHL ${ }^{2}$ \\ ${ }^{1}$ Spine Unit, Department of Orthopedic Surgery, Rigshospitalet, \\ Copenhagen University Hospital, Copenhagen, Denmark; \\ ${ }^{2}$ Division of Orthopedic Surgery, Texas Children's Hospital and Baylor College of Medicine, Houston, TX, U.S.A.
}

\begin{abstract}
Background/Aim: An increasing number of patients undergo surgical treatment for metastatic spinal cord compression (MSCC). However, the possible role of sex as an independent predictor of long-term survival has not been studied. This study aimed to examine whether sex is associated with long-term survival after surgical treatment in patients with MSCC. Patients and Methods: A total of 110 patients were operated on for MSCC from 2005 through 2006. The relation between sex and overall survival was investigated. The followup period was 10 years. Results: Survival time was significantly longer for women compared to men (mean $\pm S D$ : $29 \pm 5.2 \mathrm{vs} .14 \pm 3.6$ month ( $p=0.01)$. With adjusted analysis, this difference remained statistically significant. After adjusting for specific primary tumor type and time since surgery, the hazardratio of 10-year survival for men compared to women was 1.47 (95\% confidence intervaI $=1.01-2.18, p=0.048)$. Conclusion: These findings indicate that sex is associated with long-term survival in patients treated for MSCC.
\end{abstract}

Survival time among patients with cancer has increased within the past decades. As a result, patients suffering from spinal metastasis have also experienced an improved survival duration (1-3). With prolonged survival, the risk of severe complications follows, such as metastatic spinal cord compression (MSCC). Patients with MSCC are often acutely referred with neurological impairment and pain, and the condition has a severe negative impact on the quality of life. Yet the majority of patients are not recommended as

This article is freely accessible online.

Correspondence to: Dennis Karimi, Spine Unit, Department of Orthopedic Surgery, Rigshospitalet, Copenhagen University Hospital, Blegdamsvej 9, 2100 Copenhagen, Denmark, Tel.: +45 35453545, Fax: +45 35452165, e-mail: denniskarimi@gmail.com

Key Words: Metastatic spinal cord compression, spinal metastasis, long-term survival, surgical treatment, prognostic factor, sex. candidates for surgery because of their general condition and the short expected survival $(4,5)$.

Several pre-operative prognostic scoring systems for patients with MSCC have been developed (6-10). The conclusions from evaluations are mixed (11-14) and there is a need for continuously adapting these scoring systems as survival time increases. Based on the collection of data for a decade, we had the unique possibility to study long-term survival among patients with MSCC.

In many areas of cancer research, it has been shown that sex and survival are correlated. Women tend to live longer, and in many conditions, sex is viewed as an independent predictive factor for increased survival time (15-17). Few clinical studies have completed long-term survival analysis of patients with MSCC. The majority of long-term studies have focused on relatively specific types of primary cancer or have only included patients undergoing complex procedures (18-20).

In a prospective study with 10 years of follow-up, we aimed to examine whether sex is associated with long-term survival after surgical treatment in patients with MSCC.

\section{Patients and Methods}

Study design and population. This was a prospective consecutive cohort study. The study population included all patients with a diagnosis of MSCC referred to a single tertiary Spine Unit from January 1, 2005 to December 31, 2006. The population was previously part of a published study with a different purpose (3).

Data collection. At the time of admission, basic demographic and clinical data were prospectively registered in the Department's clinical database. At the time of follow-up, the database was reviewed and survival status was retrieved from the patient files. For the patients who underwent more than one procedure in the study period, the date of the first operation was used as the index surgery date. Corresponding to 10 years after the index surgery date, survival status was retrieved from the Department's clinical database. Five patients were excluded from the study due to osteoporosis $(n=1)$, tuberculosis spondylitis $(n=1)$ and loss to follow-up $(n=3)$. According to the National Committee on Health Research Ethics, this study did not require ethical approval nor 
patient consent but only approval for data collection. Permission to register the variables in this study was obtained through the Danish Data Protection Agency (2008-41-2128 and 2014-41-2820).

Treatment modality. All patients underwent posterior decompression and pedicle screw fixation two levels above and two levels below the level of the metastatic lesion in the spine. Postoperative radiation therapy was initiated 2 weeks later for all patients.

Statistical analysis. The hazard ratio (HR) and $95 \%$ confidence interval (CI) of change in accumulated survival time according to cancer type and sex were estimated using Cox regression. Survival in months was used as the underlying time and the follow-up ended 10 years after admission or at death, whichever came first. KaplanMeier survival curves were used to compare survival between groups. A $p$-value of less than 0.05 was considered statistically significant. All statistical calculations were made using the Stata 12.0 (Stata Corporation, TX, USA).

\section{Results}

Participants and descriptive data. A total of 110 patients were included: 59 men and 51 women. The age at surgery (mean $\pm \mathrm{SD}$ ) was $63 \pm 11.3$ years, and the mean survival time was $21 \pm 3.1$ months. When stratified by sex, the mean survival was $29 \pm 5.2$ months and $14 \pm 3.6$ months for women and men, respectively. This difference was statistically significant $(p<0.01)$. The corresponding Kaplan-Meier survival curves are depicted in Figure 1. Four women and one man survived the follow-up period of 10 years. Three of these patients were diagnosed with an unknown primary tumor, one with diffuse large-cell lymphoma and one with myeloma.

Main results. The HR of 10-year survival for men compared to women was $1.79(95 \% \mathrm{CI}=1.20-2.66, p=0.01)$. After adjusting for primary tumor site and age at surgery the HR was 1.47 (95\% $\mathrm{CI}=1.01-2.18, p=0.048)$. The distribution of primary tumor sites is shown in Table I. A total of 16 sites of primary tumors were registered. The largest subgroup was that of unknown primary tumor, followed by those of the prostate and breast, as the largest groups with known primary tumor types.

\section{Discussion}

In this prospective cohort study, there was a significantly higher 10-year survival rate in women compared to men operated for MSCC. This difference remained statistically significant after adjustments for primary tumor site and age at operation.

It is well-documented that the longevity of women is superior to that of men. It is not clear why but the survival rates women are higher for virtually all primary causes of death (21). The same pattern is not as clear among patients with MSCC. Morgen et al. assessed 1-year survival for patients with MSCC in a period of 6 years without identifying a sex-related difference (3). The largest groups in the present study with a known primary tumor were patients with prostate and breast cancer. Obviously, prostate and breast cancer are sex-specific primary tumor sites. Comparing data of the two tumor sites from The Association of Nordic Cancer registries (NORDCAN) showed similar relative survival rates for patients with prostate and those with breast cancer, including 5-year relative survival rates (1). Lung and renal cancer were also among the main primary tumors in this study. Only one woman had lung cancer as primary tumor. The relatively small sample size in the present study might explain why only one woman with lung cancer was seen. In a study by Rades et al. of a cohort of 356 patients with MSCC of nonsmall-cell lung cancer (NSCLC) the male:female ratio was 3:1 (19). Park et al. prospectively included 50 patients with MSCC derived from NSCLC who underwent surgical treatment with a follow-up of 4 years, and found no association between sex and survival (22). Lei et al. retrospectively assessed 73 patients with surgically treated MSCC with a follow-up of 3 years, and sex was not associated with survival (23). Rades et al. conducted a retrospective study assessing patients with MSCC derived from renal cell carcinoma with nearly 5-year follow-up for survivors. Sex was also not associated with survival. It should be noted, however, that the treatment modality was radiotherapy (24). It seems that studies with short-term follow-up do not find any association of sex with survival.

National, epidemiological data have shown increased incidence and mortality of cancer with age (25-29). In the present study, the relation between sex and survival duration was still statistically significant after adjusting for age. Currently, the survival duration is predicted by established scoring systems assessing a different number of predictive factors $(6-8,30)$. The most commonly used scoring systems are the revised Tokuhashi (8) and the Tomita (11) scoring systems. However, the precision in predicting survival is not optimal $(11,12,31,32)$. Some of the scoring systems were developed one or two decades ago, when surgical treatments were controversial, and radiotherapy and chemotherapy have been improved markedly since then, resulting in improved overall survival (33-35).

\section{Limitations}

Our study has some strengths and limitations that need to be considered in order to qualify the conclusion. The primary strength of the present study was its 10-year follow-up, which allowed for analysis of long-term survival. The follow-up methods via the Department's computerized clinical database enabled easy extraction of data, thus securing minimal loss to follow-up, thereby increasing the internal validity. Furthermore, an important strength was the one-center prospective, consecutive design combined with a relatively short period of enrollment. These factors ensured low variability in treatment modality and number of surgeons treating the patients. However, it could be argued that one limitation of long-term follow-up studies of patients with spinal metastasis was that 


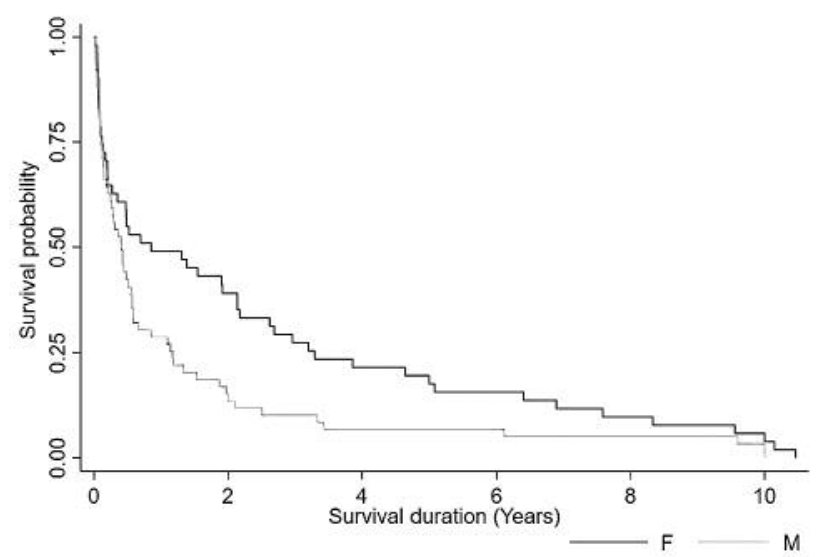

Figure 1. Kaplan-Meier curves estimated for each sex. F: Female; M: male.

the treatment of the underlying condition as well as the postoperative radiotherapy has developed considerably over the past 10 years $(35,36)$. Our treatment facility corresponds to a population of 2.2 million and the cohort is most likely representative for the entire country and probably most Western countries. In the present study, the largest group consisted of patients with unknown primary tumor, accounting for one-third of the population. This is more than previously reported in patients with spinal metastasis and may be considered as a weakness $(3,37)$. This may reflect the fact that a centralized referral system increases the number of patients with spinal metastasis as the first symptom of an oncological condition. Despite this, a similar distribution of primary tumor types has been found in other comparable studies, supporting the notion that the present cohort is representative of patients with MSCC $(35,38)$. Another limitation is that the study size only allowed for limited analysis of subgroup survival. We also acknowledge the fact that the studies conducted to develop the preoperative scoring systems in patients with spinal metastasis were based on a slightly larger sample sizes (6-8).

An increasing number of patients can be expected as longterm survivors due to earlier diagnosis, new and more effective cancer drugs, and improved surgical methods. This corroborates the need to focus on longer survival times in patients with MSCC, since these patients may be offered a more radical surgical treatment. Additional large, wellconducted prospective studies with a consistent treatment modality and a focused follow-up design regarding primary oncological diagnosis are needed.

\section{Conclusion}

This study indicates that sex is associated with long-term survival for patients undergoing surgical treatment for MSCC. Including sex as a prognostic variable may improve the selection of patients suitable for radical surgery.
Table I. The distribution of primary tumor sites of patients with metastatic spinal cord compression $(n=110)$.

\begin{tabular}{lccc}
\hline Primary tumor diagnosis & $\begin{array}{c}\text { Women } \\
(\mathrm{n}=51)\end{array}$ & $\begin{array}{c}\text { Men } \\
(\mathrm{n}=59)\end{array}$ & $\begin{array}{c}\text { Total, } \\
\mathrm{n}(\%)\end{array}$ \\
\hline Unknown primary & 23 & 16 & $39(35 \%)$ \\
Breast & 16 & 0 & $16(15 \%)$ \\
Prostate & 0 & 13 & $13(12 \%)$ \\
Lung & 1 & 7 & $8(7 \%)$ \\
Renal & 3 & 5 & $8(7 \%)$ \\
Myeloma & 2 & 4 & $6(5 \%)$ \\
Other & 1 & 5 & $6(5 \%)$ \\
Colon & 1 & 3 & $4(4 \%)$ \\
Rectum & 1 & 2 & $3(3 \%)$ \\
Bladder & 0 & 1 & $1(1 \%)$ \\
Gastric & 0 & 1 & $1(1 \%)$ \\
Diffuse large-cell lymphoma & 1 & 0 & $1(1 \%)$ \\
Melanoma & 1 & 0 & $1(1 \%)$ \\
Chondrosarcoma & 0 & 1 & $1(1 \%)$ \\
Thyroid & 1 & 0 & $1(1 \%)$ \\
Mesothelioma & 0 & 1 & $1(1 \%)$ \\
\hline
\end{tabular}

\section{Conflicts of Interest}

None to be declared.

\section{Authors' Contributions}

D.K wrote the article and carried out the statistical analysis with support from S.M. B.D and M.G conceived the presented idea and study design. All Authors provided critical feedback and contributed to shape the research, analysis and final article.

\section{Acknowledgements}

Dr. Karimi Institutional grant from The Danish Cancer Association, during the conduct of the study. Dr. Schmidt Morgen has nothing to disclose. Dr. Fruergaard reports institutional grants from The Strategic Research Counsil of Denmark during the conduct of the study. Institutional grants from Medtronic outside the submitted work. Dr. Gehrchen reports institutional grants from Medtronic and K2M outside the submitted work. Dr. Dahl reports institutional grants from The Strategic Research Council of Denmark during the conduct of the study. Institutional grants from Medtronic and $\mathrm{K} 2 \mathrm{M}$ outside the submitted work.

\section{References}

1 Engholm G, Ferlay J, Christensen N, Bray F, Gjerstorff ML, Klint A, Køtlum JE, Olafsdóttir E, Pukkala E and Storm HH: NORDCAN - a Nordic tool for cancer information, planning, quality control and research. Acta Oncol 49(5): 725-736, 2010. PMID: 20491528. DOI: 10.3109/02841861003782017

2 Taneichi H, Kaneda K, Takeda N, Abumi K and Satoh S: Risk factors and probability of vertebral body collapse in metastases of the thoracic and lumbar spine. Spine 22(3): 239-245, 1997. PMID: 9051884. DOI: 10.1097/00007632-199702010-00002 
3 Morgen SS, Lund-Andersen C, Larsen CF, Engelholm SA and Dahl B: Prognosis in patients with symptomatic metastatic spinal cord compression: survival in different cancer diagnosis in a cohort of 2321 patients. Spine 38(16): 1362-1367, 2013. PMID: 23574811. DOI: 10.1097/BRS.0b013e318294835b

4 Choi D, Fox Z, Albert T, Arts M, Balabaud L, Bunger C, Buchowski JM, Coppes MH, Depreitere B, Fehlings MG, Harrop J, Kawahara N, Martin-Benlloch JA, Massicotte EM, Mazel C, Oner FC, Peul W, Quraishi N, Tokuhashi Y, Tomita K, Verlaan JJ, Wang M and Crockard HA: Prediction of quality of life and survival after surgery for symptomatic spinal metastases: A multicenter cohort study to determine suitability for surgical treatment. Neurosurgery 77(5): 698-708, 2015. PMID: 26204361. DOI: 10.1227/NEU.0000000000000907

5 de Oliveira MF, Rotta JM and Botelho RV: Survival analysis in patients with metastatic spinal disease: the influence of surgery, histology, clinical and neurologic status. Arq Neuropsiquiatr 73(4): 330-335, 2015. PMID: 25992524. DOI: 10.1590/0004282X20150003

6 Tokuhashi Y, Matsuzaki H, Toriyama S, Kawano H and Ohsaka S: Scoring system for the preoperative evaluation of metastatic spine tumor prognosis. Spine 15(11): 1110-1113, 1990. PMID: 1702559. DOI: 10.1097/00007632-199011010-00005

7 Tokuhashi Y, Matsuzaki H, Oda H, Oshima M and Ryu J: A revised scoring system for preoperative evaluation of metastatic spine tumor prognosis. Spine 30(19): 2186-2191, 2005. PMID: 16205345. DOI: 10.1097/01.brs.0000180401.06919.a5

8 Tomita K, Kawahara N, Kobayashi T, Yoshida A, Murakami H and Akamaru T: Surgical strategy for spinal metastases. Spine 26(3): 298-306, 2001. PMID: 11224867. DOI: 10.1097/000076 32-200102010-00016

9 Van Der Linden YM, Dijkstra SPDS, Vonk EJA, Marijnen CAM and Leer JWH: Prediction of survival in patients with metastases in the spinal column: Results based on a randomized trial of radiotherapy. Cancer 103(2): 320-328, 2005. PMID: 15593360. DOI: $10.1002 / \mathrm{cncr} .20756$

10 Balain B, Jaiswal A, Trivedi JM, Eisenstein SM, Kuiper JH and Jaffray DC: The Oswestry Risk Index: An aid in the treatment of metastatic disease of the spine. Bone Joint J 95-B(2): 210216, 2013. PMID: 23365031. DOI: 10.1302/0301-620X.95B2. 29323

11 Morgen SS, Fruergaard S, Gehrchen M, Bjørck S, Engelholm SA and Dahl B: A revision of the Tokuhashi revised score improves the prognostic ability in patients with metastatic spinal cord compression. J Cancer Res Clin Oncol 144(1): 33-38, 2018. PMID: 28986702. DOI: 10.1007/s00432-017-2519-y

12 Morgen SS, Nielsen DH, Larsen CF, Søgaard R, Engelholm SA and Dahl B: Moderate precision of prognostic scoring systems in a consecutive, prospective cohort of 544 patients with metastatic spinal cord compression. J Cancer Res Clin Oncol 140(12): 2059-2064, 2014. PMID: 25035249. DOI: 10.1007/ s00432-014-1776-2

13 Tan JH, Tan K-A, Zaw AS, Thomas AC, Hey HW, Soo RA and Kumar N: Evaluation of scoring systems and prognostic factors in patients with spinal metastases from lung cancer. Spine 41(7): 638-644, 2016. PMID: 27018903. DOI: 10.1097/BRS.00000000 00001279

14 Quraishi NA, Manoharan SR, Arealis G, Khurana A, Elsayed S, Edwards KL and Boszczyket BM: Accuracy of the revised Tokuhashi score in predicting survival in patients with metastatic spinal cord compression (MSCC). Eur Spine $\mathrm{J}$ 22(Suppl 1): 21-26, 2013. PMID: 23328875. DOI: 10.1007/s0 0586-012-2649-5

15 Micheli A, Mariotto A, Giorgi Rossi A, Gatta G and Muti P: The prognostic role of gender in survival of adult cancer patients. Eur J Cancer 34(14): 2271-2278, 1998. PMID: 10070298. DOI: 10.1016/s0959-8049(98)00324-4

16 Visbal AL, Williams BA, Nichols FC, Marks RS, Jett JR, Aubry M-C, Edell ES, Wampfler JA, Molina JR and Yanget P: Gender differences in non-small-cell lung cancer survival: an analysis of 4,618 patients diagnosed between 1997 and 2002. Ann Thorac Surg 78(1): 209-215, 2004. PMID: 15223430. DOI: 10.1016/j.athoracsur.2003.11.021

17 Sugiura H, Yamada K, Sugiura T, Hida T and Mitsudomi T: Predictors of survival in patients with bone metastasis of lung cancer. Clin Orthop Relat Res 466(3): 729-736, 2008. PMID: 18196360. DOI: 10.1007/s11999-007-0051-0

18 Amendola L, Cappuccio M, De Iure F, Bandiera S, Gasbarrini A and Boriani S: En bloc resections for primary spinal tumors in 20 years of experience: effectiveness and safety. Spine J 14(11): 2608-2617, 2014. PMID: 24561037. DOI: $10.1016 /$ j.spinee.2014.02.030

19 Rades D, Douglas S, Veninga T, Bajrovic A, Stalpers LJ, Hoskin PJ, Rudat V and Schild SE: Metastatic spinal cord compression in non-small cell lung cancer patients. Prognostic factors in a series of 356 patients. Strahlenther Onkol 188(6): 472-476, 2012. PMID: 22361746. DOI: 10.1007/s00066-012-0086-3

20 Matsumoto M, Tsuji T, Iwanami A, Watanabe K, Hosogane N, Ishii K, Nakamura M, Morioka $\mathrm{H}$ and Toyama Y: Total en bloc spondylectomy for spinal metastasis of differentiated thyroid cancers: a long-term follow-up. J Spinal Disord Tech 26(4): E137-142, 2013. PMID: 23079721. DOI: 10.1097/BSD.0b013e3 $18278 \mathrm{c} 8 \mathrm{e} 4$

21 Austad SN: Why women live longer than men: Sex differences in longevity. Gend Med 3(2): 79-92, 2006. PMID: 16860268. DOI: $10.1016 / \mathrm{s} 1550-8579(06) 80198-1$

22 Park SJ, Lee CS and Chung SS: Surgical results of metastatic spinal cord compression (MSCC) from non-small cell lung cancer (NSCLC): Analysis of functional outcome, survival time, and complication. Spine J 16(3): 322-328, 2016. PMID: 26586194. DOI: 10.1016/j.spinee.2015.11.005

23 Lei M, Liu Y, Liu S, Wang L, Zhou S and Zhou J: Individual strategy for lung cancer patients with metastatic spinal cord compression. Eur J Surg Oncol 42(5): 728-734, 2016. PMID: 26924783. DOI: 10.1016/j.ejso.2016.01.018

24 Rades D, Weber A, Bartscht T, Bajrovic A, Karstens JH and Schild SE: A new prognostic factor for the survival of patients with renal cell carcinoma developing metastatic spinal cord compression. Strahlenther Onkol 190(7): 667-670, 2014. PMID: 24535650. DOI: 10.1007/s00066-014-0616-2

25 Ewertz M, Christensen K, Engholm G, Kejs AM, Lund L, Matzen LE, Pfeiffer P, Storm HH and Herrstedt J; Academy of Geriatric Cancer Research (AgeCare): Trends in cancer in the elderly population in Denmark, 1980-2012. Acta Oncol 55(Suppl 1): 1-6, 2016. PMID: 26781233. DOI: 10.3109/0284186X.2015.1114678

26 Brændegaard Winther S, Baatrup G, Pfeiffer P and Qvortrup C: Trends in colorectal cancer in the elderly in Denmark, 19802012. Acta Oncol 55(Suppl 1): 29-39, 2016. PMID: 26765865. DOI: $10.3109 / 0284186 X .2015 .1114674$ 
27 Ocias LF, Larsen TS, Vestergaard H, Friis LS, Abildgaard N and Frederiksen H: Trends in hematological cancer in the elderly in Denmark, 1980-2012. Acta Oncol 55(Suppl 1): 98-107, 2016. PMID: 26783877. DOI: 10.3109/0284186X.2015.1115124

28 Kristiansen C, Schytte T, Hansen KH, Holtved E and Hansen O: Trends in lung cancer in elderly in Denmark, 1980-2012. Acta Oncol 55(Suppl 1): 46-51, 2016. PMID: 26769559. DOI: 10.3109/0284186X.2015.1114676

29 Poulsen MH, Dysager L, Gerke O and Lund L: Trends in prostate cancer in elderly in Denmark, 1980-2012. Acta Oncol 55(Suppl 1): 74-78, 2016. PMID: 26783651. DOI: 10.3109/ 0284186X.2015.1115120

30 Rades D, Douglas S, Veninga T, Stalpers LJA, Hoskin PJ, Bajrovic A, Adamietz I, Basic H, Dunst $J$ and Schild SE: Validation and simplification of a score predicting survival in patients irradiated for metastatic spinal cord compression. Cancer 116(15): 3670-3673, 2010. PMID: 20564129. DOI: $10.1002 /$ cncr. 25223

31 Tokuhashi Y, Uei H, Oshima M and Ajiro Y: Scoring system for prediction of metastatic spine tumor prognosis. World J Orthop 5(3): 262-271, 2014. PMID: 25035829. DOI: 10.5312/wjo.v5.i3.26

32 Leithner A, Radl R, Gruber G, Hochegger M, Leithner K, Welkerling H, Rehak P and Windhager R: Predictive value of seven preoperative prognostic scoring systems for spinal metastases. Eur Spine J 17(11): 1488-1495, 2008. PMID: 18787846. DOI: $10.1007 / \mathrm{s} 00586-008-0763-1$

33 Lee BH, Kim T-H, Chong H-S, Moon E-S, Park J-O, Kim H-S, Kim S-H, Lee H-M, Cho Y-I, Kim K-N and Moon S-H: Prognostic factor analysis in patients with metastatic spine disease depending on surgery and conservative treatment: Review of 577 cases. Ann Surg Oncol 20(1): 40-46, 2012. PMID: 22956070. DOI: 10.1245/s10434-012-2644-4
34 Pointillart V, Vital J-M, Salmi R, Diallo A and Quan GM: Survival prognostic factors and clinical outcomes in patients with spinal metastases. J Cancer Res Clin Oncol 137(5): 849856, 2011. PMID: 20820803. DOI: 10.1007/s00432-010-0946-0

35 Bilsky MH, Laufer I and Burch S: Shifting paradigms in the treatment of metastatic spine disease. Spine 34(22 Suppl): S101107, 2009. PMID: 19829269. DOI: 10.1097/BRS.0b013e3 181 bac4b2

36 Rades D, Huttenlocher S, Šegedin B, Perpar A, Conde AJ, Garcia R, Veninga T, Stalpers LJ, Cacicedo J, Rudat V and Schild SE: Single-fraction versus 5-fraction radiation therapy for metastatic epidural spinal cord compression in patients with limited survival prognoses: Results of a matched-pair analysis. Int J Radiat Oncol Biol Phys 93(2): 368-372, 2015. PMID: 26232852. DOI: $10.1016 /$ j.ijrobp.2015.05.042

37 Wang M, Bünger CE, Li H, Wu C, Høy K, Niedermann B, Helmig P, Wang Y, Jensen AB, Schattiger K and Hansen ES: Predictive value of Tokuhashi scoring systems in spinal metastases, focusing on various primary tumor groups: evaluation of 448 patients in the Aarhus spinal metastases database. Spine 37(7): 573-582, 2012. PMID: 21796024. DOI: 10.1097/BRS.0b013e31822bd6b0

38 Wibmer C, Leithner A, Hofmann G, Clar H, Kapitan M, Berghold A and Windhager R: Survival analysis of 254 patients after manifestation of spinal metastases. Spine 36(23): 1977-1986, 2011. PMID: 21304424. DOI: 10.1097/BRS.0b013e3182011f84

Received January 11, 2020

Revised January 26, 2020

Accepted February 3, 2020 